\title{
ÍNDICE ACUMULADO 2007-2009
}

Os índices de autores, títulos e assuntos remetem aos números dos artigos referenciados nos anos de 2007-2009. 


\section{INSTRUÇÃO PARA USO}

O presente índice está organizado em quatro partes:

1 Referências

2 Índice Alfabético de Assuntos

3 Índice Alfabético de Autores

4 Índice Alfabético de Títulos

\section{Referências}

As referências dos artigos estão de acordo com a norma da ABNT 6023 de agosto de 2002. Estão arranjadas em ordem cronológica de edição, precedidas de numeração sequencial. Esta numeração está acima da Referência, em negrito.

Conforme exemplo:

\section{4}

SARMENTO, Manuel Jacinto. Crianças: educação, culturas e cidadania activa. Perspectiva, Florianópolis, v. 23, n. 1, p. 17-40, jan./jun. 2005. Crianças - Aspectos sociais. Crianças - Desenvolvimento. Crianças Formação.

Educação de crianças.

Número de

\section{registro}

414

Autor

SARMENTO, Manuel Jacinto

\section{Título}

Crianças: educação, culturas e cidadania activa Identificação da revista

Perspectiva, Florianópolis, v. 23, n. 1, p. 17-40, jan./jun. 2005

Palavras-chave

Crianças - Aspectos sociais. Crianças - Desenvolvimento.

Crianças - Formação. Educação de crianças. 


\section{2 Índice Alfabético de Assuntos}

O Índice Alfabético de Assuntos; é um índice de palavras-chave. Os assuntos foram indexados pela Lista de Cabeçalhos de Assuntos da Library of Congress, traduzida pela Fundação Getúlio Vargas. Estão em ordem alfabética (letra por letra), seguido abaixo pelo número de referência em negrito.

Conforme exemplo:

Crianças - Aspectos sociais

\section{4}

Crianças - Desenvolvimento

\section{4}

Crianças - Formação

\section{4}

Educação de crianças

\section{4}

\section{3 Índice Alfabético de Autores}

A entrada é efetuada pelo último sobrenome do autor em ordem alfabética (letra por letra), seguido abaixo pelo número de referência, em negrito.

Conforme exemplo:

SARMENTO, Manuel Jacinto

\section{4}

\section{4 Índice Alfabético de Títulos}

Os títulos encontram-se ordenados alfabeticamente (letra por letra), não sendo considerados os artigos definidos e indefinidos; seguidos pelo número da Referência em negrito.

Conforme exemplo:

Crianças: educação, culturas e cidadania activa.

\section{4}




\section{REFERÊNCIAS}

473

WARDE, Mirian Jorge. Repensando os estudos sociais de história da infância no Brasil. Perspectiva, Florianópolis, v. 25, n. 1, p. 21-39, jan./ jun. 2007.

Infância. Estudos sociais da infância. História da infância.

\section{4}

SIROTA, Régine. A indeterminação das fronteiras da idade. Perspectiva, Florianópolis, v. 25, n. 1, p. 41-56, jan./jun. 2007.

Infância. Sociologia da infância. Socialização. Crianças - Aspectos sociais.

\section{5}

BELLONI, Maria Luiza. Infância, mídias e educação: revisitando o conceito de socialização. Perspectiva, Florianópolis, v. 25, n. 1, p. 57-82, jan./jun. 2007.

Crianças - Aspectos sociais. Socialização.

476

MELLO, Suely Amaral. Infância e humanização: algumas considerações na perspectiva histórico cultural. Perspectiva, Florianópolis, v. 25, n. 1, p. 83-104, jan./jun. 2007.

Teoria histórico-cultural. Infância. Educação pré-escolar.

477

MONTANDON, Cleópàtre; LONGCHAMP, Philippe. Você disse autonomia? Uma breve percepção da experiência das crianças. Perspectiva, Florianópolis, v. 25, n. 1, p. 105-126, jan./jun. 2007.

Sociologia da Infância. Autonomia nas crianças. Crianças - Aspectos sociais.

\section{8}

FERREIRA, Fernando Ilídio; OLIVEIRA, Joaquim Marques de.

Escola e políticas educativas: lugares incertos da criança e da cidadania. Perspectiva, Florianópolis, v. 25, n. 1, p. 127-148, jan./jun. 2007. Programa escola a tempo inteiro. Educação e estado. Educação de crianças. Cidadania. 
479

GONZÁLEZ, Alejandro Hugo. Violencia familiar y aprendizaje: profundización de la victimización y el despojo. Perspectiva, Florianópolis, v. 25, n. 1, p. 149-169, jan./jun. 2007.

Violencia familiar - Aspectos psicológicos. Violencia - Aspectos psicológicos. Aprendizaje.

\section{0}

HERNÁNDEZ, Fernando. Narrativas en torno a las subjetividades en la escuela primaria. Perspectiva, Florianópolis, v. 25, n. 1, p. 171-206, jan./ jun. 2007.

Subjetividad. Escuelas primaria. Investigación narrativa.

\section{1}

DIONÍSIO, Maria de Lourdes. Educação e os estudos atuais sobre letramento. Perspectiva, Florianópolis, v. 25, n. 1, p. 209-224, jan./jun. 2007. Entrevista concedida à Nilcéa Lemos Pelandré e Adriana Fischer. Dionísio, Maria de Lourdes - Entrevistas.

\section{2}

PÉREZ, Andréa Lisset. Escola indígena: uma reflexão sobre seus fundamentos teóricos, ideológicos e políticos. Perspectiva, Florianópolis, v. 25, n. 1, p. 227-244, jan./jun. 2007.

Índios. Educação. Tradição. Cultura.

\section{3}

ZANARDINI, Isaura Monica Souza. A reforma do estado e da educação no contexto da ideologia da pós-modernidade. Perspectiva, Florianópolis, v. 25, n. 1, p. 245-270, jan./jun. 2007.

Reforma do estado. Educação básica. Racionalidade.

\section{4}

AVILA, Astrid Baecker; ORTIGARA, Vidalcir. Conhecimento, sociedade e educação de professores: crítica consistente ou conservadorismo político? Perspectiva, Florianópolis, v. 25, n. 2, p. 289-313, jun./dez. 2007. Educadores - Formação. Professores - Formação. Conhecimento Ontologia. 


\section{5}

BERNARDES, Maria Eliza M.; ASBAHR, Flávia Ferreira da Silva. Atividade pedagógica e o desenvolvimento das funções psicológicas superiores. Perspectiva, Florianópolis, v. 25, n. 2, p. 315-342, jul./dez. 2007. Prática pedagógica. Conhecimento e aprendizagem. Pensamento.

\section{6}

BISSOLI, Michelle de Freitas. Por uma educação para-si: algumas reflexões sobre o trabalho pedagógico. Perspectiva, Florianópolis, v. 25, n. 2, p. 343-368, jul./dez. 2007.

Educação para-si. Trabalho pedagógico. Teoria histórico-cultural.

\section{7}

CHAGAS, Liliane Maria de Moura. O ensino da língua materna: as narrativas cotidianas e literárias nos anos inicias do Ensino Fundamental. Perspectiva, Florianópolis, v. 25, n. 2, p. 369-385, jul./dez. 2007.

Narrativas cotidianas e literárias. Didática. Língua materna.

\section{8}

ZINANI, Cecil Jeanine Albert; SANTOS, Salete Rosa Pezzi dos; WAGNER, Tânia Maria Cemim. Leitura do texto literário: prazer e aquisição de conhecimentos. Perspectiva, Florianópolis, v. 25, n. 2, jul./dez. 2007. Leitura do texto literário. Zona de desenvolvimento proximal. Grupo operativo.

\section{9}

AMADO, Luiz Antonio Saléh. O trabalho docente diante da complexa relação entre educação e mercado. Perspectiva, Florianópolis, v. 25, n. 2, p. 403-424, jul./dez. 2007.

Professores - Formação. Políticas públicas. Formação docente.

\section{0}

ANTUNES, Fátima. A nova ordem educativa mundial e a União Europeia: a formação de professores dos princípios comuns ao ângulo português. Perspectiva, Florianópolis, v. 25, n. 2, p. 425-468, jul./dez. 2007. Educação e estado - Europa. Professores - Formação.

\section{1}

BUENO, Belmira Oliveira. Entre a antropologia e a história: uma perspectiva para a etnografia educacional. Perspectiva, Florianópolis, v. 
25, n. 2, p. 471-501, jul./dez. 2007.

Etnografia. Pesquisa educacional. Antropologia. História.

492

CUNHA, Maria Amália de Almeida. O conceito capital cultural em

Pierre Bourdieu e a herança etnográfica. Perspectiva, Florianópolis, v. 25, n. 2, p. 503-524, jul./dez. 2007.

Capital intelectual. Etnografia. Imperialismo. Cultura.

\section{3}

CORSETTI, Berenice. Movimento social e escola no Rio grande do Sul: um estudo no campo da história de instituiçóes educativas. Perspectiva, v. 25, n. 2, p. 525-546, jul./dez. 2007.

Movimento ferroviário. Instituições educativas. História - Rio Grande do Sul.

\section{4}

PESQUEIRA, Antonia Blanco; LORENZO, María Carmen Ricoy. Las tecnologías de la información y comunicación como recurso en el prácticum de la carreras de educación en Espańa. Perspectiva, Florianópolis, v. 25, n. 2, p. 547-578, jul./dez. 2007.

Tecnologías de la información y cominicación. Educación superior. Prácticas de enseñanza.

\section{5}

PIACENTINI, Telma Anita. A criação do Museu do Brinquedo da ilha de Santa Catarina da Universidade Federal de Santa Catarina. Perspectiva, Florianópolis, v. 25, n. 2, p. 595-610, jul./dez. 2007.

Museus. Brinquedos - museus. Cultura da infância.

\section{6}

CANÁRIO, Rui. Movimentos sociais e educação popular: lutas nas empresas, em Portugal, após o 25 de abril. Perspectiva, Florianópolis, v.26, n.1, p. 19-39, jan./jun. 2008.

Educação popular. Movimentos sociais.

\section{7}

RIBEIRO, Marlene. Educação popular: um projeto coletivo dos movimentos sociais populares. Perspectiva, Florianópolis, v. 26, n. 1, p. 41-67, jan./jun. 2008.

Educação popular. Movimentos sociais e educação. Trabalho e educação. 


\section{8}

TIRIBA, Lia. Cultura do trabalho, autogestão e formação de trabalhadores associados na produção: questóes de pesquisa. Perspectiva, Florianópolis, v. 26, n. 1, p. 69-94, jan./jun. 2008.

Trabalhadores - Formação. Trabalho.

\section{9}

FISCHER, Maria Clara Bueno. O trabalhador no centro de proposta de pesquisa-formação para o trabalho associado. Perspectiva, Florianópolis, v. 26, n. 1, jan./jun. 2008.

Trabalho. Trabalhadores - Formação. Trabalhadores - Experiências.

\section{0}

VENDRAMINI, Célia Regina. A relação entre trabalho, cooperação e educação nas pesquisas sobre o movimento dos trabalhadores rurais sem terra. Perspectiva, Florianópolis, v. 26, n. 1, p. 119-147, jan./jun. 2008. Movimento dos trabalhadores rurais sem terra. Movimentos sociais rurais. Cooperativas.

\section{1}

ZAGO, Nadir. Cursos pré-vestibulares populares: limites e perspectivas. Perspectiva, Florianópolis, v. 26, n. 1, p. 149-174, jan./ jun. 2008. Ensino superior - Seleção. Vestibulandos - Aspectos sociais.

\section{2}

RUMMERT, Sonia Maria. Educação de jovens e adultos trabalhadores no Brasil atual: do simulacro à emancipação. Perspectiva, Florianópolis, v. 26, n. 1, p. 175-208, jan./ jun. 2008.

Educação de adultos. Educação para o trabalho. Movimentos sociais.

\section{3}

ALVES, Natália. Políticas de educação-formação para jovens: tensões e contradiçôes. Perspectiva, Florianópolis, v. 26, n. 1, p. 209-230, jan./jun. 2008.

Democratização da educação. Programa iniciativa novas oportunidades.

\section{4}

CABRITO, Belmiro Gil. A creditação das aprendizagens pela experiência no acesso ao ensino superior: o caso dos maiores de 23 na Universidade de Lisboa. Perspectiva, Florianópolis, v. 26, n. 1, p. 231-250, jan./jun. 2008. 
Trabalho profissional - Experiência. Trabalho profissional Reconhecimento. Competência.

\section{5}

VIANNA, Marly de Almeida Gomes. A preocupação do movimento operário com a educação. Perspectiva, Florianópolis, v. 26, n. 1, p. 253272, jan./jun. 2008.

Movimentos sociais. Movimentos operários.

\section{6}

SANTIN, Álvaro. O movimento dos trabalhadores rurais sem terra (MST) na atualidade: luta, organização e educação. Perspectiva, Florianópolis, v. 26, n. 1, p. 275-280, jan./jun. 2008. entrevista concedida à Célia Regina Vendramini e Sonia Maria Rummert. Santin, Álvaro - Entrevistas. Movimentos sociais rurais.

\section{7}

FURLANI, Jimena. Educação sexual: quando articulação de múltiplos discursos possibilita sua inclusão curricular. Perspectiva, Florianópolis, v. 26, n. 1, p. 283-317, jan./jun. 2008.

Educação sexual. Educadores - Formação.

\section{8}

LEÃO, Geraldo Magela Pereira. Educar, ocupar, vigiar: alcances e limites de um programa para jovens pobres. Perspectiva, Florianópolis, v. 26, n. 1, p. 319-340, jan./jun. 2008.

Projeto agente jovem de desenvolvimento social. Juventude. Políticas públicas. Juventude - Aspectos sociais.

\section{9}

SUASSUNA, Lívia. Pesquisa qualitativa em educação e linguagem: histórico e validação do paradigma indiciário. Perspectiva, Florianópolis, v. 26, n. 1, p. 341-377, jan./jun. 2008.

Pesquisa educacional. Pesquisa qualitativa. Educação e linguagem Pesquisa.

\section{0}

IMEN, Pablo. Políticas educativas y modos de trabajo docente en Argentina: um recorrido por las imposiciones y resistencias entre la reproducción y la emancipación. Perspectiva, Florianópolis, v. 26, n. 2, p. 
401-432, jul./dez. 2008.

Política y Educación. Escuelas públicas. Práctica de la enseñanza.

\section{1}

DIEGUEZ, José David Alarid. Los maestros de educación básica em México (D.F.) ante la reestructuración del sector educativo. Perspectiva, Florianópolis, v. 26, n. 2, p. 433-456, jul./dez. 2008.

Educación - México. Reforma educacional - México.

\section{2}

DUARTE, Adriana. Trabalho docente na rede municipal de ensino de Belo Horizonte: análise da produçáo acadêmica. Perspectiva, Florianópolis, v. 26, n. 2, p. 457-487, jul./dez. 2008.

Trabalho docente. Produção acadêmica. Rede Municipal de Ensino de Belo Horizonte, MG.

\section{3}

SCALCON, Suze. O pragmatismo e o trabalho docente profissionalizado. Perspectiva, Florianópolis, v. 26, n. 2, p. 489-521, jul./ dez. 2008.

Professores - Formação. Pragmatismo.

\section{4}

SILVA, Mônica Ribeiro da; ABREU, Cláudia Barcelos de Moura.

Reformas para que? As políticas educacionais nos anos de 1990, o "novo projeto de formação" e os resultados das avaliaçóes nacionais. Perspectiva, Florianópolis, v. 26, n. 2, p. 523-550, jul./dez. 2008.

Reforma do ensino - Brasil. Avaliação educacional - Brasil. Políticas públicas - Brasil.

\section{5}

EVANGELISTA, Olinda. Conhecimento e diretrizes curriculares para o curso de pedagogia no Brasil. Perspectiva, Florianópolis, v. 26, n. 2, p. 551-570, jul./dez. 2008.

Pedagogia - Currículos. Educação e estado. Professores - Formação.

\section{6}

SCAFF, Elisângela Alves da Silva. Planejamento da educação: orientação global x ação local. Perspectiva, Florianópolis, v. 26, n. 2, p. 571-592, jul./dez. 2008. 
Planejamento educacional. Plano de desenvolvimento da escola. Programa Fundescola.

\section{7}

SOUZA, Magda Vianna de; CASTRO, Marta Luz Sisson de. Politização do cargo de secretário municipal de educação no estado de Santa Catarina: mudanças ocorridas no perfil profissional 1994-2004. Perspectiva, Florianópolis, v. 26, n. 2, p. 593-618, jul./dez. 2008. Secretária Municipal de Educação. Ensino de primeiro grau. Ensino fundamental. Gestão da educação municipal.

\section{8}

MARI, Cesar Luiz de. Sociedade do conhecimento: ideologia acerca da ressignificação do conhecimento. Perspectiva, Florianópolis, v. 26, n. 2, p. 619-638, jul./dez. 2008.

Educação. Conhecimento. Ideologia. Ensino superior - 1990.

\section{9}

SAVIANI, Dermeval. O curso da pedagogia e a formação de educadores. Perspectiva, Florianópolis, v. 26, n. 2, p. 641-660, jul./dez. 2008. entrevista concedida à Revista Perspectiva.

Saviani, Dermeval - Entrevistas.

\section{0}

PRETTO, Nelson de Luca; PEREIRA, Isabel C. Auler. Ensino superior no Brasil: a implantação da UNITINS e o uso da EaD como estratégia expansionista de uma universidade pública. Perspectiva, Florianópolis, v. 26, n. 2, p. 663-691, jul./dez. 2008.

Ensino superior. Universidades e faculdades - Tocantins. Políticas públicas. Ensino a distância - Tocantins.

\section{1}

LIMA, Francis Madlener de; DINIS, Nilson Fernandes. O discurso sobre a homossexualidade na visão de estudantes de educação física. Perspectiva, Florianópolis, v. 26, n. 2, p. 693-716, jul./dez. 2008.

Gênero. Educação Física. Sexo - Psicologia. Homossexualidade.

\section{2}

VOLPATO, Gildo. Sinais de inovação na docência de advogados, engenheiros e médicos professores universitários. Perspectiva, 
Florianópolis, v. 26, n. 2, p. 717-738, jul./dez. 2008.

Profissionais liberais. Ensino superior. Inovaçóes educacionais.

\section{3}

SOSSAI, Fernando Cesar; MENDES, Geovana Mendonça Lunardi;

PACHECO, José Augusto. Currículo e "novas tecnologias” em tempos de globalização. Perspectiva, Florianópolis, v. 27, n. 1, p. 19-46, jan./jun. 2009. Currículos. Globalização. Tecnologia da informação.

\section{$\mathbf{5 2 4}$}

COUTINHO, Lidia Miranda; QUARTIERO, Elisa Maria. Cultura, mídias e identidades na pós-modernidade. Perspectiva, Florianópolis, v. 27, n. 1, p. 47-68, jan./jun. 2009.

Identidade. Mídia. Identidade e cultura na pós-modernidade.

\section{5}

FANTIN, Monica; GIRARDELLO, Gilka. Diante do abismo digital: mídia-educação e mediações culturais. Perspectiva, Florianópolis, v. 27, n. 1, p. 69-96, jan./jun. 2009.

Inclusão digital. Mídia. Cidadania. Educação. Inovações tecnológicas.

\section{6}

TUFTE, Birgitte; CHRISTENSEN, Ole. Mídia-educação - entre teoria e prática. Perspectiva, Florianópolis, v. 27, n. 1, p. 97-118, jan./jun. 2009. Mídia. Tecnologia educacional. Educação - Inovações tecnológicas.

\section{7}

RIVOLTELLA, Pier Cesare. Mídia-educação e pesquisa educativa. Perspectiva, Florianópolis, v. 27, n. 1, p. 119-140, jan./jun. 2009. Mídia. Pesquisa educacional. Epistemologia. Educação - Meios auxiliares.

\section{8}

COSTA, Belarmino Cesar Guimarães da. Ambiente das mídias digitais: reflexões sobre comunicação e educação. Perspectiva, Florianópolis, v. 27, n. 1, p. 141-164, jan./jun. 2009.

Mídia. Educação - Inovações tecnológicas. Comunicação e educação.

\section{9}

GEE, James Paul. Bons videogames e boa aprendizagem. Perspectiva, Florianópolis, v. 27, n. 1, p. 167-178, jan./jun. 2009.

Videogames. Aprendizagem. Cognição. 


\section{0}

PINTO, Manuel. Uma orientação ecológica na abordagem das novas mídias e da comunicação. Perspectiva, Florianópolis, v. 27, n. 1, p. 181192, jan./jun. 2009. entrevista concedida à Monica Fantin.

Pinto, Manuel - Entrevistas. Televisão e crianças. Educação - Inovações tecnológicas.

\section{1}

VIANA, Maria José Braga. Disposições temporais de futuro e longevidade escolar em famílias populares. Perspectiva, Florianópolis, v. 27, n. 1, p. 195-215, jan./jun. 2009.

Lar e escola. Escolaridade. Família.

\section{2}

MILL, Daniel; CESÁR, Danilo. Robótica pedagógica livre: sobre inclusão sócio-digital e democratização do conhecimento. Perspectiva, Florianópolis, v. 27, n. 1, p. 217-248, jan./jun. 2009.

Robótica. Tecnologia educacional. Inclusão digital. Software livre.

\section{3}

FERRARO, Alceu Ravanello; OLIVEIRA, Jasom de. Gênero, cor/raça e níveis de letramento em Santa Catarina e Alagoas: um experimento com base em microdados do censo 2000. Perspectiva, Florianópolis, v. 27, n. 1, p. 249-271, jan./jun. 2009.

Relações homem-mulher. Raças. Alfabetização - Alagoas. Alfabetização Santa Catarina.

\section{4}

SOUZA, Ângelo Ricardo de. Conselho de escola: funções, problemas e perspectivas na gestão escolar democrática. Perspectiva, Florianópolis, v. 27, n. 1, p. 273-294, jan./jun. 2009.

Conselho de educação. Escolas - Organização e administração.

\section{5}

MORAES, Maria Célia Marcondes de. Indagaçóes sobre o conhecimento no campo da educação. Perspectiva, Florianópolis, v. 27, n. 2, p. 315-346, jul./dez. 2009.

Ciência. Ontologia crítica. Produção de conhecimento. 


\section{6}

TORRIGLIA, Patrícia Laura; DUARTE, Newton. A ciência e a produção de conhecimento na pesquisa educacional: contribuiçóes de Maria Célia Marcondes de Moraes. Perspectiva, Florianópolis, v. 27, n. 2, p. 347-374, jul./dez. 2009.

Ciência. Produção do conhecimento. Moraes, Maria Célia Marcondes de.

537

TERTULIAN, Nicolas. Sobre o método ontológico-genético em filosofia. Perspectiva, Florianópolis, v. 27, n. 2, p. 375-408, jul./dez. 2009.

Ontologia. G. Lukács. Método.

\section{8}

MACÁRIO, Epitácio. Trabalho, práxis social e educação: notas para uma teoria da atividade educativa. Perspectiva, Florianópolis, v. 27, n. 2, p. 409-440, jul./dez. 2009.

Educação. Aspectos sociais. Educação para o trabalho.

\section{9}

VAISMAN, Ester. Marx e Lukács e o problema da individualidade: algumas aproximaçóes. Perspectiva, Florianópolis, v. 27, n. 2, p. 441-459, jul./dez. 2009.

Ontologia. Lukács, György, 1885-1971. Individualidade.

\section{0}

DUARTE, Newton. Arte e educação contra o fetichismo generalizado na sociabilidade contemporânea. Perspectiva, Florianópolis, v. 27, n. 2, p. 461-479, jul./dez. 2009.

Arte e educação. Fetichismo. Sociabilidade. Alienação.

\section{1}

MORAES, Maria Célia Marcondes de; MÜLER, Ricardo Gaspar. E. P. Thompson e a pesquisa em ciências sociais. Perspectiva, Florianópolis, v. 27, n. 2, p. 481-517, jul./dez. 2009.

Ciências sociais - Pesquisa. Interação social.

\section{2}

RAJLAND, Beatriz. Rosa roja - Rosa águila: simplesmente Rosa Luxemburgo. Perspectiva, Florianópolis, v. 27, n. 2, p. 521-529, jul./dez. 2009.

Luxemburgo, Rosa, 1871-1919. 


\section{3}

MÉSZÁROS, István. Reflexões e perspectivas das relações entre capital e educaçâo. Perspectiva, Florianópolis, v. 27, n. 2, p. 533-540, jul./dez. 2009. entrevista concedida à Maria Isabel Batista Serrráo e Patrícia Laura Torriglia.

Mészáros, István - Entrevistas. Desenvolvimento humano. Capital. Educação. Produção de conhecimento. Escola. MST.

\section{4}

DONAIRE, Ricardo. Clase media o clase trabajadora? Un ejercicio empírico a partir de las percepciones de los docentes de Bueno Aires. Perspectiva, Florianópolis, v. 27, n. 2, p. 543-568, jul./dez. 2009. Docentes. Buenos Aires. Autopercepción. Clases Sociales.

\section{5}

WERLE, Flávia Obino Corrêa; WERLE, Carolina Obino Corrêa; ANDRADE, Alenis Cleusa de. Sistemas municipais de ensino no Rio Grande do Sul, Brasil: um olhar atento para o professor. Perspectiva, Florianópolis, v. 27, n. 2, p. 569-602, jul./dez. 2009. Educação e estado. Política e educação. Sistemas de ensino.

\section{6}

RIZZOTTO, Maria Lucia Frizon; NOGUEIRA, Francis Mary Guimarães. Políticas para o ensino superior no âmbito do projeto revolucionário bolivariano da Venezuela: aspectos históricos e conceituais. Perspectiva, Florianópolis, v. 27, n. 2, p. 603-628, jul./dez. 2009. Ensino superior - Venezuela. Universidade Bolivariana da Venezuela.

\section{7}

PEREIRA, Gilson Ricardo de Medeiros; ANDRADE, Maria da Conceição Lima de. A moratória profissional do magistério: ensaio de interpretação sociológica. Perspectiva, Florianópolis, v. 27, n. 2, p. 629652, jul./dez. 2009.

Professores. Formação. Carreiras - Formação. Educação permanente. 


\section{ÍNDICE ALFABÉTICO DE ASSUNTOS}

Alfabetização - Alagoas

533

Alfabetização - Santa Catarina

533

Alienação

540

Antropologia

491

Aprendizagem

529

Aprendizaje

479

Arte e educação

540

Aspectos sociais

538

Autonomia nas crianças

477

Autopercepción

544

Avaliação educacional - Brasil

514

Brinquedos - museus

495

Buenos Aires

544

Carreiras - Formação

547 
Capital

543

Capital intelectual

492

Cidadania

478; 525

Ciência

535; 536

Ciências sociais - Pesquisa

541

Clases Sociales

544

Cognição

529

Competência

504

Comunicação e educação

528

Conhecimento

518

Conhecimento e aprendizagem

485

Conhecimento - Ontologia

484

Conselho de educação

534

Cooperativas

500

Crianças - Aspectos sociais

474; 475; 477 
Cultura

482; 492

Cultura da infância

495

Currículos

523

Democratização da educação

503

Desenvolvimento humano

542

Didática

487

Dionísio, Maria de Lourdes - Entrevistas

481

Docentes

544

Educación - México

511

Educación superior

494

Educação

482; 518; 525; 538; 543

Educação básica

483

Educação de adultos

502

Educação de crianças

478

Educação e estado

478; 515; 545 
Educação e estado - Europa

490

Educação e linguagem - Pesquisa

509

Educação Física

521

Educação - Inovações tecnológicas

526; 528; 530

Educação - Meios auxiliares

527

Educação para o trabalho

502; 538

Educação para-si

486

Educação permanente

547

Educação popular

496; 497

Educação pré-escolar

476

Educação sexual

507

Educadores - Formação

483; 507

Ensino a distância - Tocantins

520

Ensino de primeiro grau

517

Ensino fundamental

517 
Ensino superior

\section{0; 522}

Ensino superior - 1990

\section{8}

Ensino superior - Seleção

501

Ensino superior - Venezuela

546

Epistemologia

527

Escola

543

Escolaridade

531

Escolas - Organização e administração

534

Escuelas primaria

480

Escuelas públicas

510

Estudos sociais da infância

473

Etnografia

491; 492

Família

531

Fetichismo

540

Formação

547 
Formação docente

489

G. Lukács

537

Gênero

521

Gestão da educação municipal

517

Globalização

523

Grupo operativo

488

História

491

História da infância

473

História - Rio Grande do Sul

493

Homossexualidade

521

Identidade

$\mathbf{5 2 4}$

Identidade e cultura na pós-modernidade

524

Ideologia

518

Imperialismo

492

Inclusão digital

525; 532 
Índios

482

Individualidade

539

Infância

473; 474; 476

Inovaçôes educacionais

522

Inovaçôes tecnológicas

525

Instituições educativas

493

Interação social

541

Investigación narrativa

480

Juventude

508

Juventude - Aspectos sociais

408

Lar e escola

531

Leitura do texto literário

488

Língua materna

487

Lukács, György, 1885-1971

539

Luxemburgo, Rosa, 1871-1919

542 
Mészáros, István - Entrevistas

542

Método

537

Mídia

524; 525; 526; 527; 528

Moraes, Maria Célia Marcondes de.

\section{6}

Movimento dos trabalhadores rurais sem terra 500

Movimento ferroviário

493

Movimentos operários

505

Movimentos sociais

496; 502; 505

Movimentos sociais e educação

497

Movimentos sociais rurais

500; 506

MST

543

Museus

495

Narrativas cotidianas e literárias

487

Ontologia

537; 539

Ontologia crítica

535 
Pedagogia - Currículos

515

Pensamento

485

Pesquisa educacional

491; 509; 527

Pesquisa qualitativa

509

Pinto, Manuel - Entrevistas

530

Planejamento educacional

516

Plano de desenvolvimento da escola

516

Política e educação

545

Política y Educación

510

Políticas públicas

489; 508; 520

Políticas públicas - Brasil

514

Prácticas de enseñanza

494

Práctica de la enseñanza

510

Pragmatismo

513

Prática pedagógica

485 
Produção acadêmica

\section{2}

Produção de conhecimento

\section{5; 536; 543}

Professores

\section{7}

Professores - Formação

484; 489; 490; 513; 515

Profissionais liberais

\section{2}

Programa escola a tempo inteiro

478

Programa Fundescola

516

Programa iniciativa novas oportunidades 503

Projeto agente jovem de desenvolvimento social

\section{8}

Raças

533

Racionalidade

483

Rede Municipal de Ensino de Belo Horizonte, MG

512

Reforma do ensino - Brasil

514

Reforma do estado

483

Reforma educacional - México

511 
Relações homem-mulher

533

Robótica

532

Santin, Álvaro - Entrevistas

506

Saviani, Dermeval - Entrevistas

519

Secretária Municipal de Educação

517

Sexo - Psicologia

521

Sistemas de ensino

545

Sociabilidade

540

Socialização

474; 475

Sociologia da infância

474; 477

Software livre

532

Subjetividad

480

Tecnologia da informação

523

Tecnologia educacional

526; 532

Tecnologías de la información y cominicación $\mathbf{4 9 4}$ 
Televisão e crianças

530

Teoria histórico-cultural

476; 486

Trabalhadores - Experiências

499

Trabalhadores - Formação

498; 499

Trabalho

498; 499

Trabalho docente

512

Trabalho e educação

497

Trabalho pedagógico

486

Trabalho profissional - Experiência

504

Trabalho profissional - Reconhecimento

504

Tradição

482

Universidade Bolivariana da Venezuela

546

Universidades e faculdades - Tocantins

520

Vestibulandos - Aspectos sociais

501

Videogames

529 
Violencia - Aspectos psicológicos

479

Violencia familiar - Aspectos psicológicos

479

Zona de desenvolvimento proximal

488 


\section{ÍNDICE ALFABÉTICO DE AUTORES}

ABREU, Cláudia Barcelos de Moura

514

ALVES, Natália

503

AMADO, Luiz Antonio Saléh

489

ANDRADE, Alenis Cleusa de

545

ANDRADE, Maria da Conceição Lima de.

547

ANTUNES, Fátima

490

ASBAHR, Flávia Ferreira da Silva

485

AVILA, Astrid Baecker

483

BELLONI, Maria Luiza

475

BERNARDES, Maria Eliza M.

485

BISSOLI, Michelle de Freitas

486

BUENO, Belmira Oliveira

491

CABRITO, Belmiro Gil

504

CANÁRIO, Rui

496 
CASTRO, Marta Luz Sisson de

517

CESÁR, Danilo

$\mathbf{5 3 2}$

CHAGAS, Liliane Maria de Moura

487

CHRISTENSEN, Ole

526

CORSETTI, Berenice

493

COSTA, Belarmino Cesar Guimarães da

528

COUTINHO, Lidia Miranda

524

CUNHA, Maria Amália de Almeida

492

DANILO, César

532

DIEGUEZ, José David Alarid

511

DINIS, Nilson Fernandes

521

DIONÍSIO, Maria de Lourdes

481

DONAIRE, Ricardo

544

DUARTE, Adriana

512

DUARTE, Newton

536; 540 
EVANGELISTA, Olinda

515

FANTIN, Monica

525

FERRARO, Alceu Ravanello

533

FERREIRA, Fernando Ilídio

478

FISCHER, Adriana

481

FISCHER, Maria Clara Bueno

499

FURLANI, Jimena

507

GEE, James Paul

529

GIRARDELLO, Gilka

525

GONZÁLEZ, Alejandro Hugo

479

HERNÁNDEZ, Fernando

480

IMEN, Pablo

510

OLIVEIRA, Jasom de

533

LEÃO, Geraldo Magela Pereira 508

LIMA, Francis Madlener de

521 
LONGCHAMP, Philippe

477

LORENZO, María Carmen Ricoy

494

MACÁRIO, Epitácio

538

MARI, Cesar Luiz de

518

MELLO, Suely Amaral

476

MENDES, Geovana Mendonça Lunardi

523

MÉSZÁROS, István

543

MILL, Daniel

532

MONTANDON, Cleópàtre

477

MORAES, Maria Célia Marcondes de

535; 541

MÜLER, Ricardo Gaspar

541

NOGUEIRA, Francis Mary Guimarães

546

OLIVEIRA, Joaquim Marques de

478

ORTIGARA, Vidalcir

483

PACHECO, José Augusto

523 
PELANDRÉ, Nilcéa Lemos

481

PEREIRA, Gilson Ricardo de Medeiros

547

PEREIRA, Isabel C. Auler

520

PÉREZ, Andréa Lisset

482

PESQUEIRA, Antonia Blanco

494

PIACENTINI, Telma Anita

495

PINTO, Manuel

530

PRETTO, Nelson de Luca

520

QUARTIERO, Elisa Maria

524

RAJLAND, Beatriz

542

RIBEIRO, Marlene

497

RIVOLTELLA, Pier Cesare

527

RIZZOTTO, Maria Lucia Frizon

546

RUMMERT, Sonia Maria

502

SANTIN, Álvaro

506 
SANTOS, Salete Rosa Pezzi dos

488

SAVIANI, Dermeval

419

SCAFF, Elisângela Alves da Silva

516

SCALCON, Suze

\section{3}

SILVA, Mônica Ribeiro da

\section{4}

SIROTA, Régine

$\mathbf{4 7 4}$

SOSSAI, Fernando Cesar

523

SOUZA, Ângelo Ricardo de

534

SOUZA, Magda Vianna de

517

SUASSUNA, Lívia

509

TERTULIAN, Nicolas

537

TIRIBA, Lia

498

TORRIGLIA, Patrícia Laura

536

TUFTE, Birgitte

526

VAISMAN, Ester

539 
VENDRAMINI, Célia Regina

500

VIANA, Maria José Braga

531

VIANNA, Marly de Almeida Gomes

505

VOLPATO, Gildo

522

ZAGO, Nadir

501

ZANARDINI, Isaura Monica Souza

483

ZINANI, Cecil Jeanine Albert

488

WAGNER, Tânia Maria Cemim

488

WARDE, Mirian Jorge

473

WERLE, Carolina Obino Corrêa

545

WERLE, Flávia Obino Corrêa

545 


\section{ÍNDICE ALFABÉTICO DE TÍTULOS}

A ciência e a produção de conhecimento na pesquisa educacional: contribuiçóes de Maria Célia Marcondes de Moraes.

536

A creditação das aprendizagens pela experiência no acesso ao ensino superior: o caso dos maiores de 23 na Universidade de Lisboa.

504

A criação do Museu do Brinquedo da ilha de Santa Catarina da Universidade Federal de Santa Catarina.

495

A indeterminação das fronteiras da idade.

474

Ambiente das mídias digitais: reflexões sobre comunicação e educação. 528

A moratória profissional do magistério: ensaio de interpretação sociológica. 547

A nova ordem educativa mundial e a União Europeia: a formação de professores dos princípios comuns ao ângulo português.

490

A preocupação do movimento operário com a educação.

505

A reforma do estado e da educação no contexto da ideologia da pósmodernidade.

\section{3}

A relação entre trabalho, cooperação e educação nas pesquisas sobre o movimento dos trabalhadores rurais sem terra.

\section{0}

Arte e educação contra o fetichismo generalizado na sociabilidade contemporânea.

540 
Atividade pedagógica e o desenvolvimento das funçôes psicológicas superiores. 485

Bons videogames e boa aprendizagem.

529

Clase media o clase trabajadora? Un ejercicio empírico a partir de las percepciones de los docentes de Bueno Aires.

\section{4}

Conhecimento e diretrizes curriculares para o curso de pedagogia no Brasil. 515

Conhecimento, sociedade e educação de professores: crítica consistente ou conservadorismo político?

\section{3}

Conselho de Escola: funçôes, problemas e perspectivas na gestão escolar democrática.

\section{4}

Cultura do trabalho, autogestão e formação de trabalhadores associados na produção: questôes de pesquisa.

\section{8}

Cultura, mídias e identidades na pós-modernidade.

524

Currículo e "novas tecnologias" em tempos de globalização.

\section{3}

Cursos pré-vestibulares populares: limites e perspectivas.

\section{1}

Diante do abismo digital: mídia-educação e mediaçóes culturais.

\section{5}

Disposiçôes temporais de futuro e longevidade escolar em famílias populares.

\section{1}

Educação de jovens e adultos trabalhadores no Brasil atual: do simulacro à emancipação.

502

Educação e os estudos atuais sobre letramento.

481 
Educação popular: um projeto coletivo dos movimentos sociais populares. 497

Educação sexual: quando articulação de múltiplos discursos possibilita sua inclusão curricular.

507

Educar, ocupar, vigiar: alcances e limites de um programa para jovens pobres.

508

Ensino superior no Brasil: a implantação da UNITINS e o uso da EaD como estratégia expansionista de uma universidade pública.

520

Entre a antropologia e a história: uma perspectiva para a etnografia educacional.

491

E. P. Thompson e a pesquisa em ciências sociais.

\section{1}

Escola e políticas educativas: lugares incertos da criança e da cidadania. 478

Escola indígena: uma reflexão sobre seus fundamentos teóricos, ideológicos e políticos.

482

Gênero, cor/raça e níveis de letramento em Santa Catarina e Alagoas: um experimento com base em microdados do censo 2000.

533

Indagaçôes sobre o conhecimento no campo da educação.

\section{5}

Infância e humanização: algumas considerações na perspectiva histórico cultural.

476

Infância, mídias e educação: revisitando o conceito de socialização.

475

Las tecnologías de la información y comunicación como recurso en el prácticum de la carreras de educación en España.

494 
Leitura do texto literário: prazer e aquisição de conhecimentos.

\section{8}

Los maestros de educación básica em México (D.F.) ante la reestructuración del sector educativo.

\section{1}

Marx e Lukács e o problema da individualidade: algumas aproximaçôes. 539

Mídia-educação - entre teoria e prática.

\section{6}

Mídia-educação e pesquisa educativa

527

Movimento social e escola no Rio grande do Sul: um estudo no campo da história de instituiçóes educativas.

493

Movimentos sociais e educação popular: lutas nas empresas, em Portugal, após o 25 de abril.

496

Narrativas en torno a las subjetividades en la escuela primaria.

\section{0}

O conceito capital cultural em Pierre Bourdieu e a herança etnográfica. 492

O curso da pedagogia e a formação de educadores.

\section{9}

O discurso sobre a homossexualidade na visão de estudantes de educação física.

521

O ensino da língua materna: as narrativas cotidianas e literárias nos anos inicias do ensino fundamental.

487

O movimento dos trabalhadores rurais sem terra (MST) na atualidade: luta, organização e educação.

506 
O pragmatismo e o trabalho docente profissionalizado.

\section{3}

O trabalhador no centro de proposta de pesquisa-formação para o trabalho associado.

499

O trabalho docente diante da complexa relação entre educação e mercado. 489

Pesquisa qualitativa em educação e linguagem: histórico e validação do paradigma indiciário.

509

Planejamento da educação: orientação global x ação local.

516

Políticas de educação-formação para jovens: tensôes e contradiçôes.

503

Políticas educativas y modos de trabajo docente en Argentina: um recorrido por las imposiciones y resistencias entre la reproducción y la emancipación. 510

Políticas para o ensino superior no âmbito do projeto revolucionário bolivariano da Venezuela: aspectos históricos e conceituais.

546

Politização do cargo de secretário municipal de educação no estado de Santa Catarina: mudanças ocorridas no perfil profissional 1994-2004. 517

Por uma educação para-si: algumas reflexôes sobre o trabalho pedagógico. 486

Reflexôes e perspectivas das relaçóes entre capital e educação.

543

Reformas para que? As políticas educacionais nos anos de 1990, o "novo projeto de formação" e os resultados das avaliações nacionais.

514

Repensando os estudos sociais de história da infância no Brasil.

473 
Robótica pedagógica livre: sobre inclusão sócio-digital e democratização do conhecimento.

\section{2}

Rosa roja - Rosa águila: simplesmente Rosa Luxemburgo.

\section{2}

Sinais de inovação na docência de advogados, engenheiros e médicos professores universitários.

\section{2}

Sistemas municipais de ensino no Rio Grande do Sul, Brasil: um olhar atento para o professor.

\section{5}

Sobre o método ontológico-genético em filosofia.

\section{7}

Sociedade do conhecimento: ideologia acerca da ressignificação do conhecimento.

\section{8}

Trabalho docente na rede municipal de ensino de Belo Horizonte: análise da produção acadêmica.

\section{2}

Trabalho, práxis social e educação: notas para uma teoria da atividade educativa.

\section{8}

Uma orientação ecológica na abordagem das novas mídias e da comunicação.

530

Violencia familiar y aprendizaje: profundización de la victimización y el despojo.

479

Você disse autonomia? Uma breve percepção da experiência das crianças. 477 


\section{NORMAS DE PUBLICAÇÃO}

A Perspectiva aceita textos inéditos nacionais e internacionais que tematizem a educação, sobretudo os decorrentes de pesquisas concluídas de caráter teórico ou empírico, análises críticas assim como ensaios que apresentem contribuiçóes sobre temas candentes da área.

A publicação dos trabalhos está condicionada a aprovação do Conselho Editorial Científico com base em pareceres de avaliadores a $d$ hoc. O sistema de avaliação é blinded-review, ou seja, os nomes dos pareceristas permanecerão em sigilo, omitindo-se também, perante estes, o nome dos autores. $\mathrm{O}$ parecer final será comunicado aos autores. Os artigos deverão ser encaminhados rigorosamente revisados, sob pena de não aceitaçáo pela Revista, pois correção de língua portuguesa e adequação às normas da ABNT são critérios considerados na avaliação. Caso os pareceristas solicitem modificaçóes no texto, ele só será publicado mediante entrega no prazo das correçôes solicitadas. Os trabalhos deverão ser acompanhados de uma declaração do(s) autor(es), autorizando sua publicação na Revista e, se aprovados, serão divulgados na forma impressa e disponibilizados eletronicamente no site da Perspectiva. Disponível em: <http://www. periodicos.ufsc.br/index.php/perspectiva/index $>$. A Perspectiva não remunera os autores que tenham seus artigos nela publicados.

A Perspectiva veicula artigos, debates, entrevistas e ensaios. As opinióes expressas nos trabalhos publicados são de responsabilidade de seus autores, não refletindo, necessariamente, a opinião da Comissão Editorial.

1. Os originais devem ter de 13 a 25 páginas e obedecer as seguintes configurações: fonte-Times New Roman 12, papel tamanho A4, espaço interlinear 1,5 com todas as margens com 2,5 cm;

2 A normalização deve obedecer a seguinte sequência: Título do artigo, em português e inglês, obrigatoriamente, e espanhol ou francês; nome(s) completo(s) dos autor(es) (no máximo 3 autores, sendo ao menos um com título de doutor); suas credenciais e local de atividade, incluindo endereço, telefone e endereço eletrônico;

3. Resumos de 100 a 250 palavras, escritos em espaço interlinear simples, em português e inglês, obrigatoriamente, e espanhol ou francês, devem conter introdução, objetivos, metodologia e conclusóes; 
4. Três palavras-chave em português e inglês, obrigatoriamente, e espanhol ou francês escolhidas no thesaurus do INEP disponível em: http://www. inep.gov.br/pesquisa/thesaurus/

5. O texto principal deve indicar os locais de inserção de ilustraçôes (quadros, fotos, mapas, modelos etc.) e de anexos ao texto, quando existirem.

6. Notas. Pede-se que as notas sejam concisas, que sua numeração obedeça rigorosamente as indicaçóes no corpo do artigo e sejam colocadas ao fim do texto. Apenas notas indispensáveis devem constar no texto. Título, resumo e identificação do autor não devem trazer notas. As referências bibliográficas não devem constar nas notas e sim serem indicadas em espaço próprio, ao final do texto.

7. As ilustraçóes, quando existirem, devem ser produzidas obedecendo ao que segue: a) Ilustraçóes: se já tiverem sido publicadas, mencionar a fonte e a permissão para reprodução; b) Quadros: deverão ser acompanhados de títulos, segundo as normas da ABNT.

8. Citação de autores: conforme NBR 10520 de agosto 2002. Devem ser feitas no corpo do texto (autor-data). As entradas pelo sobrenome do autor/vírgula/data ou autor/vírgula/data/vírgula/página sendo que quando estiverem incluídas na sentença devem ser letra maiúscula e minúscula e quando estiverem entre parênteses devem ser em letras maiúsculas. Ex: Silveira (1999, p. 20) descreve: o estudo das [...] ciências ou Artigos são os trabalhos aprovados [...] revista. ( FRANÇA, 2001, p. 51)

9. Referências: em ordem alfabética conforme NBR-6023 de agosto 2002. Exemplos:

a) Livro: CARVALHO, Diana C.; QUINTEIRO, Jucirema (Org.). Participar, brincar e aprender: exercitando os direitos da criança na escola. 1. ed. Araraquara-SP: Junqueira e Marin Editores, 2007. v. 1.

b) Capítulo de Livro: MEKSENAS, Paulo. Ideologia, Intelectuais e Dogmatismo na Ciência. In: MEKSENAS, Paulo. BIANCHETTI, Lucidio. (Org.). A trama do conhecimento: teoria, método e escrita em ciência e pesquisa. 1 ed. Campinas: Papirus, 2008, v. 1, p. 57-72.

c) Artigos de Periódicos: JANTSCH, Ari Paulo. A história continua: a formação ampliada do pequeno agricultor enquanto processo de individuação do homem universal e constituinte de um novo ser social. Reflexão e Ação, Santa Cruz do Sul, v. 12, n. 1, p. 79-89, 2004. 
d) Tese/dissertação: JANTSCH, Ari Paulo. Pequeno agricultor e racionalidade educativa. 1997. 333 f. Tese (Doutorado em Filosofia da Educação) Universidade Metodista de Piracicaba/UNIMEP, Piracicaba, 1997.

e) Artigo de jornal: FREIRE, I. M. Espetáculo a serviço do sensível. Jornal Notícias do Dia - Caderno Plural, Grande Florianópolis, p. 3-3, 3 ago. 2010. Homepage: www.escrevedance.blospot.com; Data de publicação: 03/08/2010.

f) Em meio eletrônico: TORRIGLIA, Patricia Laura; DUARTE, Newton. A ciência e a produção de conhecimento na pesquisa educacional: contribuiçóes de Maria Célia Marcondes de Moraes. Perspectiva (UFSC), Florianópolis, v. 27, n. 2, dez. 2009, p. 347-374. Disponível em: <http://www.periodicos.ufsc.br/index.php/perspectiva/article/view/15862/ pdf_2>. Acesso em: 28 dez. 2010.

g) Formato Documento Eletrônico (com DOI): EVANGELISTA, Olinda; SHIROMA, Eneida Oto. Professor: protagonista e obstáculo da reforma. Educação e Pesquisa, São Paulo, v. 33, n. 3, dez. 2007. Disponível em: <http://www.scielo.br/scielo.php?script=sci_ arttext\&pid=S1517-97022007000300010\&lng=pt\&nrm=iso $>$. Acesso em: 02 abr. 2010. doi: 10.1590/S1517-97022007000300010. 